\title{
EFEITO DE DIFERENTES FONTES DE ADUBOS ORGÂNICOS SOBRE O CRESCIMENTO E PRODUÇÃO DE ÓLEO ESSENCIAL DE EPLINGIELLA FRUTICOSA (LAMIACEAE)
}

\section{$\underline{\text { Janyne dos Santos Pereira'; }}_{-}^{1} \underline{\text { Lenaldo Muniz de Oliveira }}_{-}^{2}$; Edvan Assis de Oliveira $^{3}$}

1. Bolsista PIBIC/FAPESB, Graduanda em Agronomia, Universidade Estadual de Feira de Santana, e-mail: nini.pereira@hotmail.com

2. Orientador, Departamento de Ciências Biológicas, Universidade Estadual de Feira de Santana, e-mail: lenaldo.uefs@gmail.com

3. Mestrando, Programa de Pós-Graduação em Recursos Genéticos Vegetais/ UEFS, e-mail: edvan.oliveira@ifbaiano.edu.br

PALAVRAS-CHAVES: Plantas medicinais nativas, Cultivo, Óleos essenciais

\section{INTRODUÇÃO}

Eplingiella fruticosa (Salzm. ex Benth.) Harley \& J.F.B. é uma espécie medicinal, chamada vulgarmente de “Alecrim de vaqueiro”, pertencente a família Lamiaceae, que é conhecida por suas espécies aromáticas com grande potencial alimentício, econômico, farmacêutico. Localizada de forma nativa ou não domesticada em áreas com solo de elevada antropização, suas populações apresentam-se em aglomerados isolados no ecossistema onde se encontram. A espécie tem sido explorada no modelo extrativista pelas comunidades locais e usadas na forma de cataplasma e chás, fato que submete a espécie a elevado risco de erosão genética das populações ao longo do tempo. Estudos realizados com extratos e óleo essencial de E. fruticosa comprovaram atividades antinoceptiva, anti-inflamatória e vasodilatadora (Silva et al., 2006; Santos et al., 2007;Andrade et al., 2010; Menezes et al., 2007; Moreira et al., 2010; Franco et al., 2011; Lima et al., 2013), destacando o potencial da planta no desenvolvimento de fitoterápicos.

Embora estudos e pesquisas tenham avançado na classificação e caracterização da atividade biológica dessa espécie, pouco se sabe sobre seu cultivo, plantio ou sistemas de produção. Nessa linha, são de importância relevante pesquisas e estudos associados à domesticação da espécie. Nesse contexto, é importante o desenvolvimento de sistemas de cultivo, com bases agronômicas, bem como definição de estratégias que contribuam para a construção de um ambiente agrícola sustentável, com práticas de manejo que se adaptem ao ecossistema e ao meio ambiente, tornando assim, sua produção fonte de matéria prima para utilização na indústria da química fina.

Assim o objetivo desse trabalho foi avaliar o efeito de diferentes fontes de adubos orgânicos sobre o crescimento e produção de óleo essencial de Eplingiella fruticosa (Lamiaceae).

\section{MATERIAIS E MÉTODOS}

O experimento foi realizado na Unidade Experimental Horto Florestal da Universidade Estadual de Feira de Santana (UNEHF/UEFS), em Feira de Santana, Bahia, Brasil. O experimento foi conduzido com dois genótipos de E. fruticosa mantidos no BAG da espécie na UNEHF/UEFS. 
Para propagação dos acessos foram coletadas estacas de ramos localizados do terço médio de cada planta, com pouca lignificação e com diâmetro de aproximadamente $3 \mathrm{~mm}$. Na base inferior foi realizado um corte em bisel para evitar estrangulamento dos vasos condutores e em seguidas as extremidades seccionadas foram mergulhadas em solução a base de cobre (Sulfato de cobre) por um tempo de 10 a 12min. O Plantio foi realizado em placas de isopor com 200 células e preenchidas com substrato comercial. Após o pegamento, as mudas foram transplantadas para o local definitivo do experimento, com espaçamento de 2,0 m entre linhas e 1,0 m entre plantas. As mudas foram plantadas em covas com dimensões de 20x20x20 cm, adubadas com diferentes fontes de adubos orgânicos (cama de frango, esterco bovino e torta de mamona). Em cada cova foi aplicado 1 litro do adubo orgânico. O delineamento experimental utilizado foi de blocos casualizados, com quatro repetições, constituída de seis plantas. Como controle foi utilizado o tratamento sem adubação.

Após 180 dias de cultivo foi realizada a avaliação do crescimento, quantificado-se a altura $(\mathrm{H})$ das plantas, diâmetro da copa (Dcop), diâmetro do caule (Dcau) a $20 \mathrm{~cm}$ do solo, número de perfilhos (PERF), peso seco de folhas e flores (PSFF), peso seco do ramo (PSRam), peso seco do caule (PSCau), peso seco total (PST), teor de óleo, (TO) e rendimento de óleo (RO). Para obtenção do PSFF o material vegetal foi acondicionado em sacos de papel pardo e depositado em estufa a $60^{\circ} \mathrm{C}$, até peso constante.

A extração dos óleos essenciais foi realizada em aparelho de destilação tipo Clevenger, com tempo de destilação de 3 horas. Após a destilação, o óleo juntamente com a água, foi recolhido em um funil de separação, adicionado-se $3 \mathrm{~mL}$ de diclorometano, por três vezes, e sulfato de magnésio anidro para separação da água residual. O filtrado foi colocado em rotavapor para evaporar o diclorometano. O teor dos óleos essenciais foi quantificado pela massa de óleo em balança analítica e foi expresso em porcentagem massa/massa (mg de óleo por 100mg de matéria seca).

Todos os resultados foram submetidos à análise de variância e suas médias serão comparadas pelo teste Tukey a 5\% de probabilidade, através do programa estatístico SISVAR (FERREIRA, 2008).

\section{RESULTADOS E DISCUSSÕES}

A análise dos dados demonstrou que não houve efeito significativo para os fatores de variação acesso e adubação para as variáveis H, DCop, DCau, PERF, PSFF, PSRam, PST e Ro, contudo, verificou-se efeito significativo, na interação dos genótipos com a adubação para a variável teor de óleo (Tabela 1).

Embora não tenham diferido estatisticamente, verificou-se que a torta de mamona resultou em plantas com menores alturas, diâmetro de copa e caule e número de perfilhos, logo, indivíduos com porte mais baixo, compacto e porte mais arbustivo. De forma oposta, o tratamento com esterco 
bovino proporcionou plantas com as maiores alturas e copas mais largas. Esses atributos podem ser importantes na definição do arranjo de cultivo ao decidir, por exemplo, número de plantas por área cultivada. Nos itens que compõe a biomassa, como PSFF, PSRam, PSCau e PST, os maiores valores foram obtidos nos genótipos submetidos ao tratamento com esterco bovino e de aves (Tabela 1), embora também não tenha sido detectada diferenças estatísticas, o que pode ser explicado pelos elevados valores de coeficiente de variação $(\mathrm{CV})$ obtidos para essas variáveis.

Tabela 1. Dados médios da altura (H), diâmetro da copa (DCop), diâmetro de caule (Dcau), $\mathrm{n}^{\circ}$ de perfilhos (PERF), peso seco de folhas e flores (PSFF), peso seco de ramos (PSRam), peso seco de caule (PSCau), peso seco total (PSC), Teor de Óleo (To) e Rendimento de óleo (Ro), de dois genótipos de alecrim de vaqueiro submetidos a quatro tratamento de adubação. Feira de Santana, 2020.

\begin{tabular}{|c|c|c|c|c|c|c|c|c|c|c|}
\hline \multirow{3}{*}{ Tratamento } & \multicolumn{2}{|c|}{$\mathrm{H}(\mathrm{cm})$} & \multicolumn{2}{|c|}{ Dcop (cm) } & \multirow{2}{*}{\multicolumn{2}{|c|}{$\begin{array}{l}\text { Dcau(cm) } \\
\text { Genótipos }\end{array}$}} & \multicolumn{2}{|c|}{ PERF(und) } & \multicolumn{2}{|c|}{ PSFF(g) } \\
\hline & & & & & & & & & & \\
\hline & A & B & A & B & A & B & A & B & A & B \\
\hline Controle & $160,33 a A$ & $165,00 \mathrm{aA}$ & $151,66 a A$ & $109,33 a A$ & $13,8 a A$ & $24,10 a A$ & $3,6 a A$ & $3,6 a A$ & $100,83 a A$ & $83,33 a A$ \\
\hline Esterco aves & $152,66 \mathrm{aA}$ & $138,66 \mathrm{aA}$ & $126,66 \mathrm{aA}$ & $114,00 \mathrm{aA}$ & $62,36 a A$ & $15,80 \mathrm{aB}$ & $2,6 \mathrm{aA}$ & $3,6 a A$ & $227,00 \mathrm{aA}$ & $241,3 a A$ \\
\hline Esterco bovino & $146,66 \mathrm{aA}$ & $176,00 \mathrm{aA}$ & $166,33 a A$ & $150,33 a A$ & $15,86 a A$ & $36,90 \mathrm{aA}$ & $5,3 a A$ & $5,3 a A$ & $125,66 a A$ & $269,33 a A$ \\
\hline Torta de mamona & $177,00 \mathrm{aA}$ & $119,0 \mathrm{aA}$ & $139,33 a A$ & $95,33 a A$ & $24,80 \mathrm{aA}$ & $12,86 a A$ & $3,0 \mathrm{aA}$ & $4,0 \mathrm{aA}$ & $138,93 a A$ & $76,80 a A$ \\
\hline \multirow[t]{2}{*}{$\mathrm{CV}(\%)$} & \multicolumn{2}{|c|}{30,18} & \multicolumn{2}{|c|}{27,32} & \multicolumn{2}{|c|}{100,3} & \multicolumn{2}{|c|}{45,13} & \multicolumn{2}{|c|}{66,44} \\
\hline & PSR & $\operatorname{am}(g)$ & PSC & $\mathrm{au}(\mathrm{g})$ & PS & $\mathrm{T}(\mathrm{g})$ & & & Ro(g.p & anta-1) \\
\hline \multirow[t]{2}{*}{ Tratamento } & \multicolumn{10}{|c|}{ Genótipos } \\
\hline & $A$ & B & A & B & A & B & A & B & $A$ & B \\
\hline Controle & $97,30 a A$ & $98,56 a A$ & $50,05 a \mathrm{~A}$ & $92,82 \mathrm{aA}$ & $248,18 a A$ & $274,38 a A$ & $0,90 \mathrm{aB}$ & $0,71 \mathrm{bB}$ & $1,01 \mathrm{aA}$ & $0,57 a A$ \\
\hline Esterco aves & $210,35 \mathrm{aA}$ & $245,57 \mathrm{aA}$ & $114,44 \mathrm{aA}$ & $115,26 \mathrm{aA}$ & $551,79 a A$ & $602,13 a A$ & $0,99 a B$ & $0,68 \mathrm{bB}$ & $2,26 a A$ & $1,61 \mathrm{aA}$ \\
\hline Esterco bovino & $303,33 a A$ & $239,08 a A$ & $81,60 a A$ & $217,26 \mathrm{aA}$ & $375,92 \mathrm{aA}$ & $725,67 a A$ & $0,71 \mathrm{aB}$ & $0,62 \mathrm{bB}$ & $0,83 a A$ & $1,76 a A$ \\
\hline Torta de mamona & $273,33 a A$ & $49,11 \mathrm{aB}$ & $110,16 a A$ & $46,92 a A$ & $401,06 a A$ & $172,91 \mathrm{aA}$ & $0,81 \mathrm{aB}$ & $1,34 \mathrm{aA}$ & $1,17 \mathrm{aA}$ & $1,10 \mathrm{aA}$ \\
\hline CV(\%) & 64 & 1,10 & 87 &, 60 & 65 &, 75 & & & 66 & 33 \\
\hline
\end{tabular}

*Médias seguidas pela mesma letra minúscula na linha e pela mesma letra maiúscula na coluna não diferem entre si pelo teste de Tukey $(\mathrm{p} \leq 0,05)$.

O rendimento de óleo (g.planta ${ }^{-1}$ ) apresentado pelos dois genótipos não foi influenciado estatisticamente pelos tratamentos. Isso pode ser devido ao elevado (CV) dos dados, apurado em indivíduos silvestres submetidos a condições de crescimento e desenvolvimento diferente do seu habitat natural de ocorrência. Entretanto, o maior valor absoluto foi o apresentado pelo genótipo A, com, 2,26 g.planta ${ }^{-1}$ quando manejado com esterco avícola. Essa produtividade é superior em 22,1\% em relação ao melhor desempenho de rendimento apresentado pelo genótipo $\mathrm{B}$, que foi de 1,76 g.planta ${ }^{-1}$, quando adubado com esterco bovino.

Em plantas de Plectranthus neochilus Schltr, conhecida como boldo japonês, Silva et al. (2006) observaram que, apesar dos teores de óleo ficarem constantes, o rendimento de óleo apresentou aumento, em função do crescimento da produção de biomassa vegetal. Assim, a adubação orgânica pode não exercer influência no teor do óleo, mas pode apresentar uma contrapartida na produção da massa seca que, neste caso, pode elevar os rendimentos de princípios ativos por planta ou por área cultivada. Nesse experimento, com o alecrim-de-vaqueiro, foram aplicados, a cada genótipo, doses 
iguais do adubo (aves, bovinos e torta de mamona), equivalente a 1 litro.planta ${ }^{-1}$, em virtude de ter sido um ensaio preliminar com a espécie. Observou-se, entretanto, que não haver padronização das respostas apresentadas por cada acesso. Sendo assim, percebe-se que há divergentes respostas dos vegetais quanto ao rendimento, teor de óleo essencial e crescimento quando submetidas a doses de substratos orgânicos, criando assim uma lacuna de entendimento de que fatores ambientais ou genéticos são responsáveis pela manifestação das respostas das plantas a cada estimulo recebido do agrossistema.

\section{CONCLUSÃO}

Os resultados obtidos demonstram que os genótipos avaliados de alecrim-de-vaqueiro, espécie em domesticação, não respondem positivamente à aplicação de adubos orgânicos, nas condições de solo em que foram cultivadas, em relação aos parâmetros de crescimento, necessitando-se de estudos mais controlados para um melhor entendimento. Nesse sentido, sugere-se novos trabalhos buscandose avaliar o efeito de dosagens diferentes de adubações orgânicas.

\section{REFERÊNCIAS}

ANDRADE, A. M.; et al. Preliminary study on the anti-inflammatory and antioxidant activitiesof the leave extract of Hyptis fruticosa Salzm. ex Benth., Lamiaceae. Revista Brasileira de

Farmacognosia, v. 20, n. 6, p. 962-968, 2010;

FERREIRA, D.F. SISVAR: um programa para análises e ensino de estatística. Revista Symposium, v.6, p.36-41, 2008.

FRANCO, C. M.; et al. Bioassay guided Evaluation of Antinociceptive Properties and Chemical Variability of the Essential Oil of Hyptis fruticosa. Phytotherapy Research, v. 25, p. 1693 - 1699, 2011a;

LIMA, A. C. B.; et al. Orofacial antinociceptive effect and antioxidant properties of the hydroethanol extract of Hyptis fruticosa Salmz ex Benth. Journal of Ethnopharmacology, v.146, p. 192 - 197, 2013.

SANTOS, M. R. V. et al. Cardiovascular effects of Hyptis fruticosa essential oil in rats. Fitoterapia, v. 78, p. 186 - 191, 2007.

SILVA, A. B. L. et al. Avaliação do efeito antinociceptivo e da toxidade aguda do extrato aquoso da Hyptis fruticosa Salzm. Ex Benth. Revista Brasileira de Farmacognosia, v. 16, n. 4, pp. $475-479,2006$.

MENEZES, I. A. C.; et al. Antinociceptive effect and acute toxicity of the essential oil of Hyptisfruticosa in mice. Fitoterapia, v. 78, p. 192-195, 2007;

MOREIRA, I. J. A.; et al. Vasorelaxant effect of Hyptis fruticosa Salzm. ex Benth. Lamiaceae,dichloromethane extract on rat mesenteric artery. Revista Brasileira de Farmacognosia, v.20, n. 5, p. 762 - 766, 2010; 